Boise State University

ScholarWorks

Educational Technology Faculty Publications and

Presentations

Department of Educational Technology

$10-1-2018$

Examining Student Learning and Perceptions in Social Annotation-Based Translation Activities

Na Zhao

China Pharmaceutical University

Fei Gao

Bowling Green State University

Dazhi Yang

Boise State University 
This is an author-produced, peer-reviewed version of this article. The final, definitive version of this document can be found online at

Interactive Learning Environments, published by Routledge. Copyright restrictions may apply. doi: 10.1080/10494820.2017.1421564

\title{
Examining Student Learning and Perceptions in Social Annotation-Based Translation Activities
}

\author{
Na Zhao \\ China Pharmaceutical University
}

\author{
Fei Gao \\ Bowling Green State University
}

\author{
Dazhi Yang \\ Boise State University
}

\begin{abstract}
Limited research has been conducted on how to incorporate computer-supported collaborative learning into translation instruction despite the potential benefits. A study was conducted with a group of college English majors in China to examine the effects of using a social annotation tool to encourage student interaction during translation activities. The results showed that students made greater improvement when they completed the translation assignments with the support of a social annotation tool than when they completed the assignments in the traditional way. In addition, students had a positive attitude toward the use of the social annotation tool.
\end{abstract}

\section{Introduction}

Translating is one of the five essential abilities for university undergraduates majoring in English as a foreign language (EFL), the other four being reading, listening, speaking and writing. Since "translating consists in reproducing in the receptor language the closest natural equivalent of the source language message, first in terms of meaning and secondly in terms of style” (Nida \& Taber, 2003, p. 12), translating ability reflects a student's comprehensive mastery of both the foreign language and his mother language. To foster students' preliminary translation competence and prepare them for future professional translation work, having them practice translation both within and outside the translation classroom is crucial in an undergraduate EFL program.

The process of a traditional translation exercise usually goes like this: the instructor selects texts or language samples for students to translate "in order to identify holes in their knowledge of how to translate correctly" (Kiraly, 2000, p. 24), and when students finish their assignments alone after class, the instructor either points out students' incorrect translation in front of the class or leaves comments in the margins or between the lines of students' papers. Then students are expected to accept these comments as correct and modify "their knowledge to reflect the instructor's corrections" (Kiraly, 2000, p. 24). This teacher-centered method, which is based on the transmissionist view "where teaching and learning are understood respectively as the transmission and reception of knowledge (truth) about the world” (Kiraly, 2000, p. 23), is still widely used in EFL classrooms all over the world.

Although generations of translators have been trained using this traditional approach, there are some issues. For example, the instructor is seen as the single authoritative figure in the classroom (He, 2007), the "repository of translation equivalents and strategies that are to be made available to the entire class" (Kiraly, 2000, p. 24), and an omniscient person in possession of the "'one' correct translation” of the source text (Colina, 2003, p. 53). This "leaves little room for discussion” (Romney, 1997, p. 51) and stifles "our students' creativity, [and] their sense of responsibility toward their own learning” (Kiraly, 2000, p. 19). With the instructor as "the single judge of students' translation work" (Feng, 2001, p. 37), students are less motivated and tend to finish their assignment perfunctorily (Dai, 2011), which leads to ineffective learning (Mu, 2004). Additionally, with the traditional approach, much more attention is paid to the end product of the students' translations than to the process of translation (Feng, 2001; Wu, 2007).

To enhance students' translation competence, as well as their motivation, critical thinking, independent and life-long learning skills, it is necessary to reconsider the traditional methods adopted in translation teaching and learning. In this study, we examined the effects of a social annotation-based instructional activity on EFL learners' translation performance and learners' perceptions towards learning with the social annotation tool. 
This is an author-produced, peer-reviewed version of this article. The final, definitive version of this document can be found online at Interactive Learning Environments, published by Routledge. Copyright restrictions may apply. doi: 10.1080/10494820.2017.1421564

\section{Literature Review}

\section{Computer-Supported Collaborative Learning in Translation Instruction}

A few scholars discussed the impact that technological innovations might bring to the profession of translation and translation instruction at the beginning of the century. Kiraly (2000), for example, suggested creating a constructivist computer-based translation classroom. Feng (2001) pointed out the need for adopting computer technology in "the future of translation teaching” (p. 37) and brought forward the idea of "collaborative translating instruction” to make students' translation process public on a local area network in a computerized classroom. By "collaborative translating", he meant that students could send E-mails to each other and read each other's translations on the condition of mutual agreement, so that their consciousness as translators could be increased. Colina (2003) recommended using e-mail as a way for students to participate in class discussions, to foster students' self-confidence and self-awareness, and to help the instructor to monitor student activities and provide feedback.

Decades later, the development of technologies and the Internet drastically changed the picture of language teaching and learning. Web 2.0 technology, with its unique feature of "harnessing collective intelligence" (Li, Pow, \& Cheung, 2015, p. 2) of learners, has become an emerging focus in the area of language learning. It provides opportunities for students to learn together through various online collaboration platforms such as wikis, forums, microblogs, and social annotation tools. Computer-supported collaborative learning (CSCL), which is focused on "how collaborative learning supported by technology can enhance peer interaction and work in groups, and how collaboration and technology facilitate sharing and distributing of knowledge and expertise among community members” (Lipponen, 2002, p. 72), has been adopted abundantly in language teaching. In the field of translator education, however, most instructors still use traditional teaching methods, and there is "a lack of research on translation pedagogy" (H.-C. Wang, 2013, p. 959). Only limited empirical studies on CSCL in translation teaching have been published to date.

Chinese scholars explored the possibilities of integrating various information technologies, such as BBS, Blackboard learning management system, QQ (a Chinese counterpart of Skype), and WeChat into undergraduate translation instruction (Dai, 2011; Duan, 2008; He, 2007; L. Wang \& Dai, 2015; Ye, 2007). He (2007) pointed out that students were motivated in the e-learning platform. Students valued the work of their classmates and provided thoughtful comments on other's work, which, in return, facilitated the learning and knowledge co-construction processes among the learners. A case study conducted by Duan (2008) showed that, as a supplement to regular translation teaching, the online learning activities hosted on the Blackboard learning management system helped to create an autonomous, collaborative and interactive learning environment. To encourage sufficient and effective interaction between learners, Duan (2009) conducted another study on the effectiveness of an asynchronous interactive translation activity. Students were divided into groups of three. Two of the group members reviewed the third student's translation and posted their reviews online. The student translator responded to them respectively. This approach led to multiple rounds of interaction between the reviewers and the translator in each team, and the results showed that student interaction was of large quantity and high quality.

Venkatesan, Biuk-Aghai, and Notari (2014) utilized the platform of Transwiki to implement the social constructivist approach to teach translation. Transwiki, an online platform for collaboration, was developed to allow instructors to monitor the discussions that took place either simultaneously or asynchronously in different groups and provide scaffolding at appropriate time and place when needed. Students' discussion could be viewed by the instructor through the "history" function of Transwiki, thus providing quantitative data of every user's participation and contribution. The study showed that an important advantage of collaborating through Transwiki in comparison to traditional faceto-face group discussions was that it mitigated certain cultural and socio-psychological factors that might negatively affect the quality of collaboration, such as the values of conformity and harmony in Chinese culture.

Among the small number of studies on CSCL in translation teaching and learning, few scholars have explored the function of social annotation tools. Since one of the affordances of social annotation tools is allowing users to make targeted comments on specific sections of the text (Johnson, Archibald, \& Tenenbaum, 2010; Sun \& Gao, 2014; Wolfe, 2008), a mechanism that other Web 2.0 tools such as wikis, blog and threaded forums lack, social annotation tools seem to be particularly suitable for translation activities. Such tools allow students to have discussions on ways to translate a specific word or sentence, and thus facilitate the development of a deeper and broader understanding of the source text. 
This is an author-produced, peer-reviewed version of this article. The final, definitive version of this document can be found online at Interactive Learning Environments, published by Routledge. Copyright restrictions may apply. doi: 10.1080/10494820.2017.1421564

\section{Annotation Tools and Language Learning}

Annotation is “an important part of reading, writing and scholarship” (Marshall, 1997, p. 131). It may include underlining, highlighting, and brief notes between lines and symbols (Marshall, 1997). Annotations may be used to signal important information (Lu \& Deng, 2013), for future reference (Lebow, Lick, \& Hartman, 2009) or to be used "as an indication of something needing to be changed or addressed in a document" (Mendenhall \& Johnson, 2010, p. 264). Making annotations can (a) facilitate deep understanding of texts, since learners have to "think about the content that they are about to annotate in order to ensure both the relevance and the worth of their thoughts" (Su, Yang, Hwang, \& Zhang, 2010, pp. 752-753), (b) catch the attention of other learners so that they can focus on specific content, and (c) facilitate future learners' understanding of the material (Su et al., 2010; Wolfe, 2002).

With the development of online social annotation tools, users are able to make annotations on an electronic resource by adding comments, highlights or sticky notes, and easily share it with others (Novak, Razzouk, \& Johnson, 2012). This emerging technology has the potential to foster newer and higher levels of knowledge and information sharing by offering "a social platform for interaction and discussions" (Novak et al., 2012, p. 40). Studies about the use of social annotation tools for language learning have mainly focused on reading and writing. Research suggests that deeper thinking might be promoted when students worked in small groups on reading tasks using social annotation tools (Mendenhall \& Johnson, 2010). Such activities facilitate the development of higher-level cognitive abilities such as analyzing, summarizing, and evaluating (Yang, Yu, \& Sun, 2013), encourage more attentive, reflective and critical learning (Lu \& Deng, 2013), and also have the potential to improve students' learning (I.-J. Chen \& Chen, 2015; Liu \& Lan, 2016; H.-C. Yeh, Hung, \& Chiang, 2017). Similarly, researchers who studied the effect of social annotation supported writing activities argue that social annotation tools offer students opportunities to provide feedback to each other's writing, and help them focus their attention on the parts that they need to work on in the document (S. Yeh \& Lo, 2009).

Although there are multiple studies on using social annotation tools to engage language learners in reading or writing activities, we did not find any studies examining the use of social annotation tools and translating, an activity that requires language skills in both reading and writing. It is believed that using social annotation as a collaborative tool may have the potential to improve student learning in translating activities because social annotation tools can facilitate both the reading and writing processes (C.-M. Chen \& Chen, 2014; Storch, 2005; Wolfe, 2008; Yang et al., 2013). Collaborative annotations of the texts may allow students to share their different understandings of source text, evaluate their expressions in the target language, share different versions of translation, and get inspiration from other students' comments. In addition, the asynchronous nature of such activities frees students from time and space constraints (Gao, 2013; Samuel, Kim, \& Johnson, 2011), and thus students may spend more time reviewing the texts, reflecting on peers' comments, searching for additional information, and refining their translations. This study examined student learning and perceptions of their learning experience in social annotation-based translation activities. By examining student perceptions, we aimed to gain an understanding of how students feel about using the technology to interact and learn, as well as their expectations and needs (Halic, Lee, Paulus, \& Spence, 2010). This could help inform future implementations of similar instructional activities (Halic et al., 2010; Hamid, Waycott, Kurnia, \& Chang, 2015). As a result, we addressed the following two research questions in the study:

1. Did students perform better when they completed translation activities by interacting with each other using a social annotation tool than when they completed translation activities in the traditional way?

2. How did students perceive their learning with the social annotation tool?

\section{Method}

\section{Participants and Settings}

Participants were 5 male and 36 female English majors from two sections of an English Translation class in a southeast university in China. The two sections were taught by the same instructor, using the same curriculum. Student ages were between 19 and 22 years old, with a mean of 20.33 and a standard deviation of 0.80 . None of the students had any experience with social annotation tools prior to the study. The mean and standard deviation of students' Test for English Majors-Band 4 (TEM-4) scores were 70.60 and 6. 46 respectively, with the lowest score being 55 and the highest being 83. TEM-4 and TEM-8 are national standardized tests to measure the English proficiency of Chinese university undergraduates majoring in English Language and Literature, and are considered reliable and valid tests of 
This is an author-produced, peer-reviewed version of this article. The final, definitive version of this document can be found online at Interactive Learning Environments, published by Routledge. Copyright restrictions may apply. doi: 10.1080/10494820.2017.1421564

student English proficiency(Jin \& Fan, 2011). The TEM-8 translation evaluation rubric was later used in this study as the evaluation rubric for student translation assignments (See Appendix A). An independent t-test suggested no significant difference between students' TEM-4 scores across the two sections. It is worth noting that a crossover design was adopted (see Procedures section) to control any student differences across the two sections. In a crossover design, a comparison is made of the participant's performance in Condition 1 vs. Condition 2. Therefore, the rigor of the study would not be affected even if there were a significant difference between the TEM-4 scores across the two sections.

\section{Procedures}

At the beginning of the semester, students in both sections were introduced to the social annotation tool in Zoho Docs (www.zoho.com/docs/). Zoho Docs is similar to Google Docs, and it was chosen because it was one of the few social annotation tools that were available in China with relatively stable access and quality service. The instructor provided students a detailed written tutorial on how to get a Zoho account, how to share documents online via Zoho Docs, and how to make comments on each other's documents. Then, students were asked to complete several simple activities using the social annotation tool. The last activity was very similar to the activities that they were to complete during the experiment, where students were asked to critique each other's translation work using the Zoho social annotation tool, then revise and resubmit their work based on the comments received from their peers.

The experiment was carried out two weeks after students were introduced to the Zoho social annotation tool. Crossover design was used to control the student differences between the two sections (see Table 1). For translation assignment 1, students in Section A completed the assignment in the Zoho social annotation-based environment (Condition 1), while students in Section B completed it individually (Condition 2). For translation assignment 2, the conditions were reversed, with students in Section B using the Zoho social annotation environment (Condition 1), and students in Section A completing the assignment individually (Condition 2).

Table 1. Design of the Study

\begin{tabular}{lll}
\hline & $\begin{array}{l}\text { Assignment 1 } \\
\text { (Week 1-4) }\end{array}$ & $\begin{array}{c}\text { Assignment 2 } \\
\text { (Week 5-8) }\end{array}$ \\
$\begin{array}{l}\text { Condition 1: } \\
\text { With Zoho Social Annotation tool }\end{array}$ & Section A & Section B \\
$\begin{array}{l}\text { Condition 2: } \\
\text { Without Zoho Social Annotation tool }\end{array}$ & Section B & Section A \\
\hline
\end{tabular}

In week 1, students in Section A completed the translation assignment 1 and shared their work on Zoho. In week 2, each student in Section A was assigned to review five students' (or six in some rare cases) translation assignments, which were randomly picked by the instructor, and comment on these assignments using the Zoho social annotation tool. They were required to post at least two comments to each of their classmates' work and were encouraged to respond to comments received from their peers. The instructor joined the discussion after at least three or four students had posted their comments. She intentionally chose not to participate at the very early stage, so that students had some time to work independently before they were exposed to more authoritative opinions. During this phase, the instructor made comments to acknowledge good thinking, corrected misunderstandings, redirected misleading comments, and pointed out things that were ignored by the groups. All participants were asked to turn on the notification function in Zoho, so that they were aware of all new comments made on the shared documents. In week 3, students in Section A revised their translation work based on (a) the comments provided by their classmates; (b) the comments provided by the instructor, and (c) what they had learned from reviewing others' work. They submitted their revisions via Zoho by the end of the week along with a reflective journal documenting their learning processes and the problems that they encountered during the process. In contrast, students in Section B received traditional instruction. Students completed the translation assignment 1 and submitted their work directly to the instructor via Zoho in week 1 . In week 2, they received instructors' comments, which provided instructions for them to clarify or re-examine their previous translations, and they were asked to reflect on the instructor's comments and think about ways to further improve their translation. They were encouraged to discuss their work with their peers or schedule individual meetings with the instructor whenever necessary. Then, students submitted a revision of their previous work as well as a reflective 
This is an author-produced, peer-reviewed version of this article. The final, definitive version of this document can be found online at Interactive Learning Environments, published by Routledge. Copyright restrictions may apply. doi: 10.1080/10494820.2017.1421564

journal by the end of week 3 . In week 4's face-to-face class, the instructor debriefed with students in both sections by sharing with them the most common mistakes and issues in this assignment. Similarly, from week 5 to week 8, students in both sections worked on assignment 2 following the design presented in Table 1. A follow-up survey asking students to reflect on their learning experiences was administered in week 8 immediately following the two learning activities.

\section{$\underline{\text { Data Analysis }}$}

\section{Learning Outcomes}

Both the first versions and the second versions of student translation work were submitted to and graded by the instructor. The instructor assigned a score ranging from 0 to 8 to each student's work based on the evaluation rubric (see Appendix A). A second rater graded the assignments based on the same rubric, and the scores were compared. Inter-rater reliability was calculated to ensure the reliability of grading. First, percentage of agreement was measured by calculating the percent of exact or adjacent agreement (within 1 point) between the grading sets. The percentage of exact agreement was $55.83 \%$, and the percentage of adjacent agreement was $92.24 \%$, which suggested a good level of consensus (Jonsson \& Svingby, 2007; Stemler, 2004). Second, level of consistency in grading was measured by the Pearson correlation and the Cronbach's alpha. The results showed a strong correlation between the two, $r(82)=.81$, $p=.00$, two-tailed, and the Cronbach's alpha was .86. Both exceeded the acceptable values (Jonsson \& Svingby, 2007; Stemler, 2004).

\section{Perceived Learning}

The perceived learning survey consisted of three sections of Likert-scale questions that measured: (a) perceived individual learning, (b) perceived collaborative learning, and (c) perceived overall learning when student participated in the Zoho social annotation supported activities. A few open-ended questions were asked at the end of each section that invited students to explain their ratings in detail. For example, students were asked to "explain as detailed as possible why you rate it that way." Student responses to the open-ended questions in the survey were coded using a grounded theory approach (Glaser \& Strauss, 1967) to identify major themes. The results were used to support the quantitative analyses. For example, when a significant difference was found in favor of one environment over the other, students' responses were used to understand why students preferred that environment.

\section{Results}

\section{Learning Outcomes}

The means and standard deviations of student grades on the translation assignments in both conditions are presented in Table 2. ANOVA was conducted by setting (a) condition, (b) section, (c) assignment, and (d) student (nested in section) as independent variables. The dependent variable was the student grade difference between the first and second submission. The analysis suggested that factors including section, assignment and student (nested in section) had no effect on the grade differences. The only factor that impacted student learning was condition (see Table 3). The student grade differences were significantly higher when students were in Condition 1: with social annotation tool $($ Mean $=1.61 ; \mathrm{SD}=0.76)$ than when they were in Condition 2: without social annotation tool (Mean =1.18; SD $=0.73)$.

Table 2. Means (Standard Deviations) of Student Grades on Translation Assignments in Both Conditions. ( $n=41)$

\begin{tabular}{lll}
\hline & $\mathbf{1}^{\text {st }}$ Submission & $2^{\text {nd }}$ Submission \\
\hline Condition 1 & $5.28(0.84)$ & $6.89(0.66)$ \\
Condition 2 & $5.27(0.87)$ & $6.45(0.93)$ \\
\hline
\end{tabular}


This is an author-produced, peer-reviewed version of this article. The final, definitive version of this document can be found online at Interactive Learning Environments, published by Routledge. Copyright restrictions may apply. doi: 10.1080/10494820.2017.1421564

Table 3. Estimated Marginal Means and Standard Deviations of Student Grade Differences in the Two Conditions $(n=41)$

\begin{tabular}{llllll}
\hline & Means & SDs & F & p & $\boldsymbol{\eta}^{2}$ \\
\hline Condition 1 & 1.61 & 0.76 & 6.52 & .015 & .14 \\
Condition 2 & 1.18 & 0.73 & & & \\
\hline
\end{tabular}

\section{Perceived Learning}

Student responses to Likert questions in the survey were coded into numbers ranging from -3 (not at all) to 3 (very well). Instead of running multiple ANOVA tests, MANOVAs were conducted to control Type I error. The results suggested that students had a positive attitude toward learning with the Zoho social annotation tool in terms of individual learning, which focused on how students interacted individually with the shared documents $[F(4,37)=$ 26.49, $\left.p<.001, \eta_{p}^{2}=.74\right]$. They also had a positive attitude towards collaborative learning, which focused how students interacted with other students $\left[F(4,37)=16.49, p<.001, \eta_{p}{ }^{2}=.64\right]$. They believed that learning activities were more effective when the Zoho social annotation tool was adopted $\left[F(3,38)=10.58, p<.001, \eta_{p}{ }^{2}=.45\right]$. The follow-up ANOVAs suggested that the mean of student ratings to each Likert question was significantly higher than 0 (see Table 4).

Table 4. Means and Standard Deviations of Student Responses to Likert Questions ( $n=41)$

\begin{tabular}{|c|c|}
\hline Survey Items & Means (SDs) \\
\hline \multicolumn{2}{|l|}{ Category I: Individual Learning } \\
\hline $\begin{array}{l}\text { (1) Pay specific attention to your classmates' translation of specific words or } \\
\text { sentences }\end{array}$ & $1.12(0.95)^{* *}$ \\
\hline (2) Provide in-depth analysis of your classmates' translation & $0.73(1.16)^{* *}$ \\
\hline $\begin{array}{l}\text { (3) Timely record your thoughts and ideas that you would like to share with } \\
\text { your classmates }\end{array}$ & $0.46(1.23)^{*}$ \\
\hline $\begin{array}{l}\text { (4) Change or improve your own translation after reading and commenting } \\
\text { on your classmates' work }\end{array}$ & $1.20(0.78)^{* *}$ \\
\hline $\begin{array}{l}\text { Category II: Collaborative Learning } \\
\text { How well do you think that the Zoho annotation tool supports you to: } \\
\text { (1) Exchange ideas and opinions on correct/alternative ways of translation } \\
\text { with your classmates }\end{array}$ & $1.05(10.97)^{* *}$ \\
\hline (2) Negotiate possible ways of translation with your classmates & $0.71(1.17) * *$ \\
\hline $\begin{array}{l}\text { (3) Change or improve your own translation based on your conversation } \\
\text { with your classmates }\end{array}$ & $1.05(1.14) * *$ \\
\hline (4) Communicate effectively with your classmates & $0.46(1.16) *$ \\
\hline
\end{tabular}


This is an author-produced, peer-reviewed version of this article. The final, definitive version of this document can be found online at Interactive Learning Environments, published by Routledge. Copyright restrictions may apply. doi: 10.1080/10494820.2017.1421564

\section{Category III: Overall Learning}

(1) When comparing your learning experience while working on the two assignments, do you think the use of the Zoho annotation tool better support the processes of translation?

(2) When comparing your learning experience while working on the two assignments, do you think the use of the Zoho annotation tool help you make greater improvement in your translation?

(3) When comparing your learning experience while working on the two assignments, do you think you learn better from the assignment supported by the Zoho annotation tool?
$0.68(1.11) * *$

$0.90(1.02) * *$

$0.76(0.99) * *$

* $\mathrm{p}<.05 ; * * \mathrm{p}<.005$

Several recurring themes were identified from student responses to open-ended questions, which explained students' preferences for using the Zoho annotation tool. First, a number of students (12 students) indicated that using the Zoho annotation tool greatly facilitated student-student communication and interaction. According to the students, the Zoho annotation tool facilitated the exchange of ideas because the conversations could go beyond the classroom. Students could interact with their classmates anytime no matter where they were (S11). In addition, because all the comments were recorded electronically online, students were able to access the comments whenever necessary (S16).

Second, many students (19 students) expressed that they had learned a lot through participating in the Zoho annotation tool supported activity. Specifically, they mentioned that they learned through the process of reading their classmates' work, reflecting on their classmates' comments, and having conversations with their classmates. Some students felt that they benefited from reading their peers' work because it allowed them to (they learned through the process of reading their classmates' work, reflecting on their classmates' comments, and having conversations with their classmates. ["Sometimes, I did not have a good understanding of the text. Comparing my classmates' work with mine helped me see the meaning of the text that I did not fully understand previously" (S36)]; (b) see the problems in their own translation ["reading my classmates' work helped me see the problems in my own translation" (S33)]; (c) gain insights on how to improve their own translation ["I read all my classmates' work carefully, especially those good ones. I can borrow some of their ideas or use the translation strategies they used to improve my own translation" (S35)]; and (d) be aware of possible mistakes ["I could see where my classmates' made mistakes and what kind of improvement was needed, which prevented me from making similar mistakes” (S36)]. There were 4 students who explicitly expressed that their classmates' feedback was helpful: "I received a lot of invaluable suggestions from my classmates, and gained better understanding of those long, hard-to-understand sentences in the original text” (S1). A few others expressed that the conversations with their classmates were beneficial because the conversations exposed them to multiple perspectives, and allowed them to work together to solve problems and co-construct meanings. "When I encounter a problem during translation, I usually take a random guess or discuss it with one or two of my classmates. With Zoho, I can exchange ideas with multiple students and view their work at the same time” (S35). "Sometimes, I could see that my classmates and I share the same questions. Through discussion, we could put our wits together and come up with a better translation" (S36). Students felt the collaborative learning experience supported by the Zoho annotation tool was better than the traditional instructor-only mode: "It was rather limiting to receive feedback solely from the instructor. In some cases, I still had questions or doubts even after reading the instructor's comments” (S33), and “... I was still uncertain of my translation when I submitted the revision. Reading my classmates' translation and interacting with them allowed me to better understand the text and therefore come up with a more adequate translation” (S18).

Another theme identified from student comments was the recognition of the important role of the instructor. They recognized the benefits of receiving instructor's comments, and expressed concerns of relying solely on their peers: "There are times when none of us know how to come up with the correct translation" (S10), and "The discussion with peers may not necessarily lead to the right answer. There were times that after a long discussion, the translation we came up with was still not ideal” (S20). Though the instructor jumped in and interacted with the students right after the majority finished posting two comments to the reviewed work, some students felt that they would like to see more and earlier participation from the instructor, so that the instructor could correct mistakes in the comments (S5) and address the challenging issues (S8) in a more timely manner. 
This is an author-produced, peer-reviewed version of this article. The final, definitive version of this document can be found online at Interactive Learning Environments, published by Routledge. Copyright restrictions may apply. doi: 10.1080/10494820.2017.1421564

While students acknowledged the positive effects of the Zoho annotation tool supported activity, they identified a few drawbacks. Eight complained that the system was slow and three commented on the unstable function of sending out email reminders when a new comment was added. In addition, some students felt that communication could be further enhanced if anytime anywhere access to the documents was made possible through, for example, a Zoho smartphone application: "We could not edit the documents or make comments on our smart phones, which made it impossible to have immediate access to my instructor and classmates' feedback or to respond to their comments in a timely manner" (S28). When students were not getting timely responses from peers, they lost the momentum of learning and thus wasted potential learning opportunities: "Sometimes, just because someone could not respond to a comment in time, a conversation that could potentially be quite fruitful ended prematurely” (S32).

\section{Discussion}

The study investigated the effects of social annotation supported collaborative translation activities on student translation assignment grades, and examined student perceived learning experience in the social annotation supported environment. Overall, the analysis of student learning and perceptions suggests some positive effects of the social annotation supported translation activities.

First, although students participating in both types of activities scored higher in their second submissions than in their first submissions, students, when completing the assignments in the social annotation environment had significantly greater gains than when they completed the assignments in the traditional environment. This finding is consistent with those from previous studies on the effectiveness of using annotation tools to support reading and writing (I.-J. Chen \& Chen, 2015; Mendenhall \& Johnson, 2010; Wolfe, 2002; Yang et al., 2013).

Second, student ratings on their perceived learning suggested that they believed that the use of the social annotation tool positively impacted their learning. They felt that the social annotation tool supported the process of translation, and they were able to make improvements in their translations. Two students commented that working in the social annotation environment was fun and enjoyable. Particularly, they felt that they could open up and have more relaxed and natural conversations when they shared opinions and had discussions about the translations. Students seemed to be more motivated due to the social nature of the activities. This is consistent with previous studies, which suggested that technology-mediated collaborative activities have the potential to enhance student motivation (Reid, 2014; Samuel et al., 2011).

Third, student responses to the open-ended survey questions explained how the social annotation environment facilitated the processes of both individual learning and collaborative learning. First, it encouraged self-reflection. Reading peers' work provoked students to reflect on both their classmates' and their own translations. The reflections led to better understanding of the original text, enhanced awareness of alternative translations or translation strategies, and improvements in their own translations. Second, it increased the opportunities of communication and knowledge co-construction. When working together in the social annotation environment, students raised questions, had discussions, proposed solutions, reconciled their understanding, and, as a result, improved their translations.

\section{Limitations, Pedagogical Implications, and Future Research}

The study is one of the first studies that examined the effects of using social annotation tool to improve EFL student translation. The results suggested that having students work on their translations in a social annotation supported environment positively impacted their learning. The analysis of student survey responses shed light on how the use of a social annotation tool affects student learning processes. There are, however, a few limitations. First, during the study, the instructor was aware of what condition the students were in. As a result, she might have been biased in how she provided feedback to the students in the two conditions. A double blind study would have been a better option. Second, the majority of the participants were female. Since gender may have an impact on online communication patterns (Prinsen, Volman, \& Terwel, 2007), caution should be taken when generalizing the research findings. Third, the study only reported the immediate benefit of social annotation-based translation activities. There was no post-test examining whether students learned more. Finally, students only completed one assignment in the social annotation based environment. The short time span of the study has made it difficult to evaluate the actual benefits of such activities in a long term. 
This is an author-produced, peer-reviewed version of this article. The final, definitive version of this document can be found online at Interactive Learning Environments, published by Routledge. Copyright restrictions may apply. doi: 10.1080/10494820.2017.1421564

This study has a few pedagogical implications on teaching translation with social annotation tools. Having students review and comment on each other's translations using social annotation tools provides opportunities for students to learn from each other, improve their own work, and solve problems collectively. The results of this study suggest that timely student-student communication is essential to ensure the success of collaborative learning. Valuable learning opportunities may get lost when some students fail to respond to their peers' comments or do not respond in a timely manner. In this study, students were required to post at least two comments to each assignment that they reviewed. It might be helpful if students were also required to respond to the comments that they have received from their peers. Setting up deadlines on when students are expected to respond may also help encourage timely communication and sustained discussions. Another factor that seems to impact student experiences of learning is instructor's intervention. Though there is no specific rule of when the instructor should step in, student survey responses suggest that there are several occasions that instructors' intervention may be particularly beneficial. For example, when a mistake or misunderstanding goes unnoticed by most of the students involved in the discussion, the instructor may have to correct the mistake or misunderstanding. Similarly, when a group of students attempt but fail to come up with a reasonable solution or reach consensus, the instructor may want to provide additional guidance or point them to the right direction. Finally, when a potentially productive conversation stops prematurely, the instructor may also decide to intervene and find ways to encourage further discussion.

This study also suggests some directions for future research. First, it is important to examine the effects of grouping on student learning. Lu and Deng (2013) examined how a high-performance class (HPC) and an ordinary-performance class (OPC) used Diigo to support their argumentative reading activities and found that the HPC made significantly more sticky notes than the OPC. In this study, each student was randomly assigned to review five or six students' work. It is worth investigating whether grouping students by English language proficiency (for example, matching high-performing students with low-performing students), learning style, or gender would impact learning. Second, the study examined student learning outcomes and their perceived learning, but it did not investigate student motivation or its relation to student learning. Future research could be conducted to see whether how student motivation is related to their learning in such translation activities. This would help us answer questions such as "Are highly motivated students more likely to have greater improvement in their work?" or "Are highly motivated students those who receive higher scores but not necessarily those who make greater improvements?” Third, improving student translation skills is a long-term process. Though the results of this study suggest that students had greater improvement when they completed the assignments in the social annotation environment as compared to the traditional environment, it is still unknown whether the proposed approach is more effective in improving student translation skills over a long period of time. Longitudinal studies are needed to track student performance and improvement over time so as to understand not only whether this approach works better than the traditional approach but also how it works.

\section{References}

Chen, C.-M., \& Chen, F.-Y. (2014). Enhancing digital reading performance with a collaborative reading annotation system. Computers \& Education, 77, 67-81. doi: http://dx.doi.org/10.1016/j.compedu.2014.04.010

Chen, I.-J., \& Chen, W.-C. (2015). Perceived usefulness of a strategy-based peer annotation system for improving academic reading comprehension. Journal of Interactive Learning Research, 27(1), 27-51.

Colina, S. (2003). Translation teaching: from research to the classroom. Boston: MaGraw-Hill.

Dai, J. C. (2011). Study on the construction and application of QQ-based interactive after-class translation teaching model. Computer-assisted Foreign Language Education, 138, 61-66.

Duan, Z. (2008). Integrating network translation course into translation teaching. Chinese Translators Journal, 2, 46-50.

Duan, Z. (2009). An empirical study on campus Internet-based peer review and interactive translation training. Chinese Translators Journal, 3, 44-49.

Feng, Y.-h. (2001). Collaborative translating instruction on classroom net. Chinese Translators Journal, 2, 37-40.

Gao, F. (2013). A case study of using a social annotation tool to support collaboratively learning. The Internet \& Higher Education, 17, 76-83.

Halic, O., Lee, D., Paulus, T., \& Spence, M. (2010). To blog or not to blog: Student perceptions of blog effectiveness for learning in a college-level course. The Internet and Higher Education, 13(4), 206-213. doi:10.1016/j.iheduc.2010.04.001 
This is an author-produced, peer-reviewed version of this article. The final, definitive version of this document can be found online at Interactive Learning Environments, published by Routledge. Copyright restrictions may apply. doi: 10.1080/10494820.2017.1421564

Hamid, S., Waycott, J., Kurnia, S., \& Chang, S. T. (2015). Understanding students' perceptions of the benefits of online social networking use for teaching and learning. INTERNET AND HIGHER EDUCATION, 26, 1-9. doi:10.1016/j.iheduc.2015.02.004

He, Y. (2007). BBS As a new platform for translator education. Chinese Translators Journal, 6, 29-32.

Jin, Y., \& Fan, J. (2011). Test for English majors (TEM) in China. Language Testing, 28(4), 589-596.

Johnson, T. E., Archibald, T. N., \& Tenenbaum, G. (2010). Individual and team annotation effects on students' reading comprehension, critical thinking, and meta-cognitive skills. Computers in Human Behavior, 26(6), 1496-1507. doi:10.1016/j.chb.2010.05.014

Jonsson, A., \& Svingby, G. (2007). The use of scoring rubrics: Reliability, validity and educational consequences. Educational Research Review, 2(2), 130-144. doi:10.1016/j.edurev.2007.05.002

Kiraly, D. (2000). A social constructivist approach to translator education. Manchester, UK: St. Jerome.

Lebow, D. G., Lick, D. W., \& Hartman, H. (2009). New technology for empowering virtual communities. In M. Pagani (Ed.), Encyclopedia of Multimedia and Technology (pp. 1066-1071). Hershey, PA: IGI Global.

Li, S. C., Pow, J. W. C., \& Cheung, W. C. (2015). A delineation of the cognitive processes manifested in a social annotation environment. Journal of Computer Assisted Learning, 31(1), 1-13. doi:10.1111/jcal.12073

Lipponen, L. (2002). Exploring foundations for computer-supported collaborative learning. Paper presented at the Proceedings of the Conference on Computer Support for Collaborative Learning: Foundations for a CSCL Community, Boulder, Colorado.

Liu, S. H.-J., \& Lan, Y.-J. (2016). Social constructivist approach to web-based EFL learning: Collaboration, motivation, and perception on the use of Google Docs. Journal of Educational Technology \& Society, 19(1), 171.

Lu, J., \& Deng, L. (2013). Examining students' use of online annotation tools in support of argumentative reading. Australasian Journal of Educational Technology, 29(2), 161-171.

Marshall, C. C. (1997). Annotation: from paper books to the digital library. Paper presented at the ACM International Conference on Digital Libraries.

Mendenhall, A., \& Johnson, T. E. (2010). Fostering the development of critical thinking skills, and reading comprehension of undergraduates using a Web 2.0 tool coupled with a learning system. Interactive Learning Environments, 18(3), 263-276. doi:10.1080/10494820.2010.500537

$\mathrm{Mu}, \mathrm{L}$. (2004). Pathways to the development of translation teaching. Chinese Translators Journal, 5, 25-26.

Nida, E. A., \& Taber, C. R. (2003). The theory and practice of translation (Vol. 8). Brill.

Novak, E., Razzouk, R., \& Johnson, T. E. (2012). The educational use of social annotation tools in higher education: A literature review. The Internet and Higher Education, 15(1), 39-49. doi:10.1016/j.iheduc.2011.09.002

Prinsen, F. R., Volman, M. L. L., \& Terwel, J. (2007). Gender-related differences in computer-mediated communication and computer-supported collaborative learning. Journal of Computer Assisted Learning, 23(5), 393-409. doi:10.1111/j.1365-2729.2007.00224.x

Reid, A. J. (2014). A case study in social annotation of digital text. Journal of Applied Learning Technology, 4(2), $15-25$.

Romney, J. C. (1997). Collaborative learning in a translation course. The Canadian Modern language Review, 54(1), 48-67.

Samuel, R. D., Kim, C., \& Johnson, T. E. (2011). A study of a social annotation modeling learning system. Journal of Educational Computing Research, 45(1), 117-137.

Stemler, S. E. (2004). A Comparison of consensus, consistency, and measurement approaches to estimating interrater reliability. Practical Assessment, 9(4), 1-11.

Storch, N. (2005). Collaborative writing: Product, process, and students' reflections. Journal of Second Language Writing, 14(3), 153-173.

Su, A. Y. S., Yang, S. J. H., Hwang, W.-Y., \& Zhang, J. (2010). A Web 2.0-based collaborative annotation system for enhancing knowledge sharing in collaborative learning environments. Computers \& Education, 55(2), 752-766. doi:10.1016/j.compedu.2010.03.008

Sun, Y., \& Gao, F. (2014). Web annotation and threaded forum: How did learners use the two environments in an online discussion? The Journal of Information Technology Education: Innovations in Practice, 13, 69-88.

Venkatesan, H., Biuk-Aghai, R. P., \& Notari, M. (2014). Collaborative learning of translation: The case of TransWiki in Macao. Paper presented at the International Symposium on Open Collaboration.

Wang, H.-C. (2013). Rationales for cooperative tasks in Taiwan translation learning. Journal of Language Teaching and Research, Vol. 4(5), 958-964.

Wang, L., \& Dai, J. (2015). The construction and application of the WeChat-based mobile interactive translation teaching model. Computer-assisted Foreign Language Education(162), 35-41. 
This is an author-produced, peer-reviewed version of this article. The final, definitive version of this document can be found online at

Interactive Learning Environments, published by Routledge. Copyright restrictions may apply. doi: 10.1080/10494820.2017.1421564

Wolfe, J. (2002). Annotation technologies: A software and research review. Computers \& Composition, $19(4), 471$.

Wolfe, J. (2008). Annotations and the collaborative digital library: Effects of an aligned annotation interface on student argumentation and reading strategies. International Journal of Computer-Supported Collaborative Learning, 3(2), 141-164. doi:10.1007/s11412-008-9040-x

Wu, X. J. (2007). An interactive approach of translation teaching. Foreign Language Research, 137, $121-123$.

Yang, X., Yu, S., \& Sun, Z. (2013). The effect of collaborative annotation on Chinese reading level in primary schools in China. British Journal of Educational Technology, 44(1), 95-111. doi:10.1111/j.14678535.2011.01277.x

Ye, M. (2007). A study of the interactive teaching mode of translation. Foreign Language World, 3, 51-56+91.

Yeh, H.-C., Hung, H.-T., \& Chiang, Y.-H. (2017). The use of online annotations in reading instruction and its impact on students' reading progress and processes. ReCALL : the Journal of EUROCALL, 29(1), 22. doi:10.1017/S0958344016000021

Yeh, S., \& Lo, J. (2009). Using online annotations to support error correction and corrective feedback. Computers and Education, 52(4), 882-892. doi:10.1016/j.compedu.2008.12.014

\section{APPENDIX A.}

\section{Student Translation Evaluation Rubric}

\begin{tabular}{ll}
\hline Categories & Criteria \\
\hline Excellent & The translation faithfully reflects all of the original passage with only 1 or 2 \\
9-10 points & minor errors in vocabulary, syntax, punctuation or spelling. The translation is \\
& elegant (appropriate choice of words, a variety in sentence patterns). \\
Good & The translation reflects almost all the original passage with relatively few \\
7-8 points & significant errors of vocabulary, syntax, spelling or punctuation. The translation \\
& is readable (generally clear, smooth and cohesive). \\
Acceptable & The translation adequately reflects most of the original passage with occasional \\
5-6 points & errors of vocabulary, syntax, spelling or punctuation. The translation is, for the \\
& most part, readable. \\
Inadequate & The translation only reflects about half of the original passage with frequent \\
3-4 points & errors of vocabulary, syntax, spelling or punctuation. The translation is, in some \\
& parts, unreadable. \\
Poor & The translation reflects less than half of the original passage. Almost all \\
1-2 points & sentences contain errors of vocabulary, syntax, spelling or punctuation. The \\
& translation is, for the most part, unreadable. \\
\hline
\end{tabular}

